\title{
TRANSPLANTE AUTÓLOGO DE MEDULA ÓSSEA E IMUNOTERAPIA PÓS-TRANSPLANTE
}

\author{
AUTOLOGUS BONE MARROW TRANSPLANTATION AND POSTTRANSPLANT IMMUNOTHERAPY
}

\author{
Celso Massumoto ${ }^{1} \&$ Sally Mizukami ${ }^{2}$
}

\begin{abstract}
${ }^{1}$ Responsável pelo Serviço de Transplante de Medula Óssea. ${ }^{2}$ Responsável pelo Laboratório de Criopreservação. Centro de Oncologia do Hospital Sírio Libanês \& Centro de Hemoterapia São Lucas, São Paulo-SP.

CorReSPONDÊNCIA: Dona Adna Jafet, 91 - $9^{2}$ andar - CEP: 01308-050 - São Paulo - SP. E-mail:cmass@attglobal.net
\end{abstract}

MASSUMOTO C \& MIZUKAMI S. Transplante autólogo de medula óssea e imunoterapia pós-transplante. Medicina, Ribeirão Preto, 33: 405-414, out./dez. 2000.

RESUMO: Altas doses de quimioterapia, seguidas da infusão de stem cells hematopoéticas, é a terapêutica de escolha para uma variedade de neoplasias hematológicas e tumores sólidos. O transplante autólogo apresenta, associada ao procedimento, menor taxa de mortalidade, se comparado com o transplante alogênico de medula óssea, porém, as taxas de recidiva são superiores a este último e semelhantes às dos transplantes singênicos, e os resultados clínicos dependem da doença de base e do seu estadiamento clínico. A sobrevida livre de doença é maior quando os pacientes são transplantados sem evidência de doença ou com doença residual mínima, e é reduzida quando o transplante é realizado em estádios mais avançados. A terapia celular adotiva se refere ao emprego de linfócitos alogênicos como agentes do tratamento antitumoral. Por outro lado, a base racional para o emprego da Interleucina-2, nos transplantes autólogos de medula óssea, é a inexistência de barreira imunológica entre doador e receptor e a possível eliminação de células residuais que foram infundidas com a medula óssea. Como as recidivas costumam ocorrer nos primeiros meses após o transplante, a imunoterapia deve ser utilizada precocemente no contexto de doença residual mínima.

UNITERMOS: Transplante de Medula Ossea. Transplante Autólogo. Interleucina-2. Imunoterapia.

\section{INTRODUÇÃO}

O conceito de altas doses de quimioterapia seguidas da infusão de stem cells hematopoéticas foi incorporado ao contexto terapêutico com a finalidade de cura para uma série de neoplasias hematológicas e tumores sólidos. A utilização dessa estratégia terapêutica, denominada classicamente transplante de medula óssea (TMO), tem crescido exponencialmente nos últimos anos ${ }^{(1)}$.

Como parte do procedimento de TMO, seja ele autólogo ou alogênico, a medula óssea (MO) ou o sangue periférico são utilizados como fonte de célu- las-tronco hematopoéticas (CTH) ou stem cells hematopoéticas $(\mathrm{SCH})$, que irão promover a recuperação hematológica após o tratamento, com a quimioterapia em altas doses. Mais recentemente, as células do cordão umbilical vêm sendo empregadas como fonte alternativa de stem cells ${ }^{(2)}$.

Avanços importantes referentes ao TMO, utilizando stem cells hematopoéticas, provenientes da $\mathrm{MO}^{(3)}$ ou do sangue periférico ${ }^{(4)}$, ocorreram nas últimas décadas, evidenciando o potencial dessas células em restaurar a hematopoiese após rádio e/ou quimioterapia ablativas. Apesar de, atualmente, os transplantes autólogos serem realizados quase que exclusiva- 
mente com CTH, obtidas do sangue periférico, nesta revisão, esses transplantes serão tratados sob a denominação comum de TMO.

Vários estudos demonstraram as vantagens clínicas do emprego do TMO, utilizando $\mathrm{SCH}$ do sangue periférico (SCHSP), sobre a medula óssea, dentre elas, uma recuperação hematopoética mais rápida, resultando em menor morbidade, redução do número de transfusões de plaquetas e concentrado de glóbulos vermelhos e uma diminuição do período de antibioticoterapia. Além disso, as SCHSP podem ser coletadas sem anestesia geral e não há necessidade do emprego de técnicas invasivas, como na coleta da medula óssea por via pélvica, em centro cirúrgico ${ }^{(4)}$.

\section{COLETA E CRIOPRESERVAÇÃO DE CÉLULAS TRONCO HEMATOPOÉTICAS}

\subsection{Coleta de stem cells}

Stem cells hematopoéticas podem ser coletadas da medula óssea pela técnica clássica descrita por Storb et al. do grupo de Seattle ${ }^{(5)}$. Resumidamente, com o paciente sob anestesia geral ou espinal e em decúbito ventral, faz-se a aspiração da medula óssea por meio de agulhas de Thomas de $3-5 \mathrm{ml}$ por vez, em um total de $10-20 \mathrm{ml} / \mathrm{kg}$ do receptor ou $2,0-4,0 \times 10^{8}$ células totais nucleadas $/ \mathrm{kg}$. Outra maneira é por meio de separadores celulares que coletam um grande número de leucócitos do sangue periférico, através de leucoaféreses ${ }^{(6)}$. Normalmente, o volume do circuito extracorpóreo é anticoagulado, usando-se dextrose adenina-citrato (ACD) na proporção de 30:1 com o sangue. Parestesias de região labial são raras e, nos casos de troca volumétrica maiores (denominadas de trocas de grandes volumes) ${ }^{(7)}$, faz-se a reposição de cálcio por via oral. A complicação mais séria é a redução do número de plaquetas (geralmente em torno de $30 \%$ ) após a leucoaférese. O monitoramento das células CD34+ no sangue periférico é, hoje, empregado nos centros de transplante de medula ${ }^{(6)}$. Admitese, de modo geral, que um valor superior a $2,5 \times 10^{6}$ células CD34+/kg do receptor seja necessário para garantir um enxertamento adequado.

\subsection{Criopreservação das células pluripotentes hematopoéticas}

Uma etapa muito importante no transplante autólogo de medula óssea é a criopreservação da medula óssea ou das células tronco-hematopoéticas periféricas. A criopreservação permite a administração de regimes de condicionamento por vários dias, como, também, o armazenamento profilático para pacientes a serem transplantados meses ou anos mais tarde.

O fato de que a célula-tronco hematopoética pode ser criopreservada com sucesso é evidenciado pela capacidade da mesma de regenerar a função da medula após regimes com altas doses de quimioterapia. A falha na recuperação hematopoética, geralmente, não é atribuída à criopreservação de células pluripotentes hematopoéticas. Porém, alguns investigadores correlacionam uma má criopreservação de células pluripotentes com o atraso na recuperação hematopoética, após o transplante ${ }^{(8,9)}$.

$\mathrm{Na}$ Criobiologia, a formação de cristais de gelo durante o congelamento é a causa primária de danos celulares. Cristais de gelo intracelulares podem se formar durante o congelamento rápido, resultando em uma ruptura mecânica das estruturas celulares. Sob congelamento lento, a formação de cristais de gelo ocorre no espaço extracelular, resultando em um aumento da osmolaridade, à medida que a água livre é incorporada aos cristais de gelo. Essa diminuição de água resulta na concentração de solutos extracelulares, tais como os íons de sódio, que não atravessam livremente a membrana celular (ou são ativamente excluídos), podendo causar uma hiperosmolaridade extracelular, levando a uma desidratação celular. Em um congelamento lento, é provável que a formação de gelo ocorra primeiramente fora da célula. Uma desidratação progressiva da célula irá ocorrer se o congelamento for excessivamente lento, permitindo uma passagem da água para o espaço extracelular, que poderá ser incorporada ao crescimento dos cristais de gelo. Parece que a permeabilidade da célula à água é que define a razão ótima de congelamento para qualquer célula em particular.

Existem dois métodos de criopreservação. Um deles é realizado pelo congelamento rápido das células, quando a medula ou as células-tronco periféricas são colocadas diretamente em um freezer a $-80^{\circ} \mathrm{C}$ e a concentração final da solução crioprotetora é de $5 \%$ de dimetilsulfóxido (DMSO), $6 \%$ de solução de amido hidroxietilamido e $4 \%$ de albumina humana em solução salina. $\mathrm{O}$ outro método realiza o congelamento lento e progressivo, quando a razão de decaimento da temperatura é controlada por computador. Nele, a solução crioprotetora é constituída por $40 \%$ de meio de cultura, $40 \%$ de plasma autólogo e $20 \%$ de DMSO. A técnica de congelamento lento e descongelamento rápido evita os danos mecânicos e a desidratação causada pela formação e crescimento de cristais de gelo. $\mathrm{O}$ descongelamento das células deve ser rápido para 
que os cristais de gelo, formados durante o congelamento, não danifiquem a membrana celular ${ }^{(10)}$.

\subsection{CD34: $O$ antígeno marcador da célula-tron- co hematopoética}

O marcador CD34 é uma glicoproteína de superfície, expressa em células progenitoras e linfoematopoéticas bem imaturas, em células endoteliais e em fibroblastos embriônicos. As células CD34+ da medula óssea correspondem somente a $1,5 \%$ das células mononucleares medulares, mas contêm precursores para todas as linhagens linfoematopoéticas, o que é evidenciado pela descoberta de que células CD34+, purificadas da medula óssea, podem reconstituir a hematopoese em primatas, humanos ou camundongos que são submetidos ao transplante de medula óssea. As células CD34+ hematopoéticas, obtidas da medula óssea ou do sangue periférico, têm uso clínico em transplante de medula e em estudos de terapia gênica, incluindo a expansão de células-tronco "ex vivo". O CD34 foi descoberto a partir do desenvolvimento de anticorpos que reconhecem especificamente uma pequena fração de células da medula óssea humana, mas não reconhecem células linfóides ou células sangüíneas maduras. O primeiro anticorpo CD34, o My10, foi um produto do hibridoma gerado de um camundongo imunizado com a linhagem celular KG1a de leucemia mielóide ${ }^{(11)}$.

Os anticorpos CD34, especificamente, detectam uma média de apenas $1,5 \%$ de células mononucleares de baixa densidade, de aspirados de medula óssea de doadores normais. Em contraste, há menos de $0,5 \%$ de células $\mathrm{CD} 34+$ no sangue periférico não mobilizado. A população de células CD34+, de medula óssea humana normal é rica em células blásticas, em contraste com a fração de células CD34-, que contêm, predominantemente, células precursoras em diversos estágios de maturação da hematopoiese.

As vantagens da contagem de células CD34+ sobre a contagem morfológica diferencial e o ensaio de cultura de células hematopoéticas são a sua objetividade, precisão e rapidez (menos de 24 horas para a obtenção do resultado). A contagem é largamente empregada para se decidir quando obter células-tronco hematopoéticas, mobilizadas do sangue periférico. Empregando a mobilização com quimioterapia, a porcentagem de células CD34+ pode aumentar para $1 \%$ a $5 \%$. A contagem de células CD34+ pode prever a recuperação de células progenitoras, que podem ser coletadas por leucoaférese ${ }^{(12)}$.

As células-tronco hematopoéticas podem ser mobilizadas da medula óssea através de quimioterapia ou da associação desta com fatores de crescimento. Estudos recentes demonstram que o fenômeno de mobilização depende das moléculas de adesão e de seus ligantes na medula óssea, e o mecanismo de mobilização das células progenitoras hematopoéticas envolve a estimulação inicial da migração celular através do rompimento da interação VLA4/VCAM-1, associado a um mecanismo cooperativo de sinalização, envolvendo as moléculas (c-kit/c-kit ligante). Assim, acreditase que esta via de estímulo, (c-kit/c-kit ligante, possa ser uma via comum de sinalização acionada pelos diferentes estímulos de mobilização ${ }^{(13)}$.

Uma mobilização eficiente não é alcançada somente com o estímulo inicial às moléculas de adesão, é necessário, também, que haja uma sinalização cooperativa, gerada através do uso de fatores de crescimento (G-CSF, GM-CSF). Além disso, os fatores de crescimento atuam sinergisticamente com os quimioterápicos, levando a um aumento da proliferação celular ${ }^{(14)}$.

\section{PRINCIPAIS INTERCORRÊNCIAS DO TRANSPLANTE AUTÓLOGO DE MEDU- LA ÓSSEA}

\subsection{Doença venoclusiva hepática}

Entre o oitavo e vigésimo dia após o TMO, uma síndrome clínica, caracterizada por hepatomegalia, icterícia e retenção de fluidos se desenvolve em $10 \%$ a $60 \%$ dos pacientes. A síndrome é devida a uma lesão das células endoteliais dos sinusóides e dos hepatócitos na área próxima às veias hepáticas de pequeno calibre, e sua causa mais provável é a terapia citorredutiva do condicionamento. Alterações histológicas no fígado incluem a trombose das veias hepáticas, dilatação e aumento dos sinusóides e necrose dos hepatócitos. Essa síndrome, geralmente denominada VOD (venocclusive disease) do fígado, pode variar, em severidade, de grau leve até a falência de múltiplos órgãos, levando ao óbito ${ }^{(15)}$.

\subsection{Pneumonias intersticiais}

A pneumonite intersticial, causada por citomegalovírus (CMV), geralmente, ocorre de um a dois meses após o transplante de medula óssea, e é uma das maiores causas de morbidade e mortalidade. Aproximadamente $16 \%$ dos receptores de medula óssea alogênica desenvolvem pneumonia por CMV; o índice de mortalidade era superior a $95 \%$ até a recente introdução da antigenemia e o início do tratamento precoce. A pneumonia por CMV parece derivar de uma 
combinação dos efeitos da replicação viral com os mecanismos imunopatológicos do receptor. A pneumonite se desenvolve secundariamente a uma reativação do vírus, latente em pacientes soropositivos, ou como uma infecção primária transmitida a receptores soronegativos ao receberem medula óssea ou produtos sanguíneos soropositivos. Nos receptores de transplantes autólogos, a incidência de pneumonite por CMV é significativamente menor do que nos transplantes alogênicos, mas ela aumenta quando as células T são removidas do enxerto, como nos transplantes autólogos de células CD34 purificadas (vide cap. XII).

A pneumonia intersticial não bacteriana é, também, uma causa significante de morbidade após transplante de medula óssea. Enquanto, em alguns casos, é secundária a outros agentes virais ou ao Pneumocystis carinii, na maioria das vezes, é de causa idiopática. Acredita-se que a pneumonia idiopática ocorra parcialmente devido à toxicidade da quimioterapia em altas doses, utilizada nos regimes de condicionamento. A incidência de pneumonite intersticial é maior em pacientes com doença do enxerto-contra-hospedeiro e também está relacionada com a idade ${ }^{(16)}$.

\subsection{Infecções}

O transplante autólogo com células tronco-hematopoéticas, mobilizadas para o sangue periférico, produz um período de neutropenia significativamente inferior ao verificado no transplante alogênico de medula óssea, acarretando uma freqüência muito menor de infecções bacterianas e fúngicas na fase pós-transplante, imediata. Ademais, devido à ausência de reação do enxerto-contra-hospedeiro, pelo menos em sua forma grave, e da necessidade de profilaxia imunossupressora para ela, as infecções oportunistas, como as causadas por CMV, EBV, Herpes e $P$. carini, por exemplo, também são reduzidas nos transplantes autólogos não manipulados, se comparadas às ocorridas nos transplantes alogênicos. Entretanto, essas infecções podem constituir problema, quando se depletam células imunocompetentes do transplante, como pela seleção positiva de células CD34 (vide Capítulos V e XII deste Simpósio).

\subsection{Recidivas}

Um dos principais problemas do transplante autólogo de medula óssea é a alta taxa de recidiva. Várias estratégias podem ser aplicadas a ele, tais como a purificação do enxerto, empregando-se anticorpos monoclonais, duplos transplantes e a imunoterapia póstransplante, como será discutido na Secção 5.

\section{RESULTADOS CLÍNICOS DO TRANS- PLANTE AUTÓLOGO DE MEDULA ÓSSEA}

\subsection{Tumores sólidos}

1) Neuroblastoma: embora haja uma grande sensibilidade do tumor à quimioterapia, ela cura menos de $20 \%$ dos pacientes. A maioria deles apresenta-se para transplante com a forma avançada da doença. Mesmo assim, o emprego do TMO melhorou a sobrevida global e a sobrevida livre de doença no neuroblastoma, porém, os resultados foram modestos (vide Capítulo III deste Simpósio).

2) Sarcoma de Ewing: estudos de fase II demonstram que $25 \%$ dos pacientes pediátricos atingem remissão completa com quimioterapia convencional nos estádios avançados. Os resultados com TMO autólogo não demonstram superioridade em relação à quimioterapia convencional.

3) Rabdomiossarcoma: as taxas de cura situam-se em $20 \%$ para os pacientes com doença metastática. Os resultados com transplante de stem cells periféricas são desapontadores em tal situação.

4) Câncer de testículo: esse tipo de tumor tem grande quimiossensibilidade. Em pacientes que não são refratários à cisplatina e que não têm doença extragonadal, existe uma chance de $20 \%$ de cura com a quimioterapia. Os fatores prognósticos envolvidos incluem progressão da doença, doença mediastinal e níveis elevados de B-HCG (human corionic gonadotrophin). Os alvos de interesse das investigações do TMO consistem na doença de mau prognóstico não tratada e na primeira recidiva após terapia convencional. Pico et al. exploraram o emprego de altas doses de ciclofosfamida e de ifosfamida em pacientes refratários, e os estudos confirmam uma ótima resposta (50 a 70\%), com remissões completas, variando de 13 a mais de $70 \%$, com 20 a $50 \%$ de sobrevida livre de doença em 18 meses de seguimento médio. Tais achados confirmam a utilidade de altas doses de quimioterapia nesta patologia ${ }^{(17)}$.

5) Câncer de mama: os ensaios clínicos do National Cancer Institute (protocolo PBT1) compararam, de modo randomizado, a sobrevida global, toxicidade e qualidade de vida em mulheres que responderam ao tratamento padrão para a forma metastática e receberam, em seguida, o protocolo STAMP V (ciclofosfamida, tiotepa e carboplatina) e suporte de stem cell ou quimioterapia convencional (CMF). Em tal, estudo, 180 pacientes foram randomizadas, sendo 101 no grupo de TMO e 79 no grupo de quimioterapia 
do tipo CMF. Esses dados são os maiores da literatura e não se observaram diferenças na sobrevida e toxicidade dos dois regimes, embora os resultados de qualidade de vida e custos financeiros não tenham sido apresentados. Assim, as melhores candidatas para o TMO autólogo, em câncer de mama, seriam as pacientes com estádios II ou III da doença com mais de 10 gânglios axilares comprometidos pelo tumor. Resultados preliminares de dois estudos, empregando ABMT, são encorajadores e demonstraram sobrevida livre de doença, de $80 \%$ em três anos, nesse subgrupo de pacientes ${ }^{(18)}$.

6) Câncer de ovário: o grande desafio em tal patologia é a pouca quimiossensibilidade do tumor. Estudos com pacientes selecionados demonstram uma vantagem para o TMO autólogo. Assim, Shinozuka et al. (1991) administraram dois cursos de ciclofosfamida, adriamicina e cisplatina seguidos da infusão de stem cells periféricas. Nenhuma doença macroscópica foi observada no seguimento, em 23 pacientes, e a sobrevida foi de $70 \%$ em quatro anos comparada com a de $19 \%$ do grupo com doença macroscópica ${ }^{(19,20)}$.

\subsection{Doenças onco-hematológicas}

1) Doença de Hodgkin: é curável com quimioterapia convencional, na maioria dos pacientes. Porém, o TMO é uma modalidade efetiva para pacientes em recidiva ou de alto risco (estádio IV). A maioria dos regimes de condicionamento incluem o BCNU (nitrosuréia); entretanto, ela está relacionada com severa toxicidade pulmonar. Não se observou melhora dos resultados com o transplante alogênico. Dos pacientes que recidivam dentro do primeiro ano de tratamento, somente $14 \%$ conseguirão sobrevida livre de doença em quatro anos. Dentre aqueles que recidivam após um ano, a sobrevida livre de doença é de $45 \%$ com o transplante autólogo de medula óssea ${ }^{(21)}$.

2) Leucemia Mielóide Aguda: o TMO autólogo para LMA tem sido empregado em vários centros, no mundo. A sobrevida global varia de 45 a $55 \%$. Três grandes estudos demonstram baixa incidência de recidiva em pacientes adultos que se submeteram ao autotransplante. Recente estudo americano não demonstrou melhora na sobrevida entre transplante autólogo, alogênico e quimioterapia convencional em pacientes pediátricos. Muitos esforços têm sido realizados no sentido de avaliar o possível efeito da purificação da medula óssea com derivados da ciclofosfamida ${ }^{(22)}$.

3) Leucemia linfocítica aguda (LLA): transplante autólogo de stem cells periféricas em pacientes com LLA, em primeira remissão, não oferece vantagens sobre a quimioterapia convencional. Transplante em segunda remissão pode prolongar a sobrevida livre de doença ${ }^{(23)}$.

4) Mieloma múltiplo: em ensaios clínicos randomizados, de quimioterapia convencional, com transplante de medula óssea, este último demonstrou resultados superiores de sobrevida. Infelizmente, não se observa um plateau ao final da curva de sobrevida com o $\mathrm{TMO}^{(24)}$.

5) Linfomas não-Hodgkin: somente $30 \%$ a $40 \%$ dos pacientes curam-se com a terapêutica convencional. Em torno de $10 \%$ dos pacientes que recidivam tornam-se livres da doença com a terapêutica convencional. Nos pacientes em primeira recidiva, que obtêm nova remissão, o TMO autólogo é superior ( $46 \%$ versus $12 \%$ ) à quimioterapia de resgate. $\mathrm{O}$ transplante autólogo, usado como consolidação do tratamento, em pacientes com linfoma de grau intermediário, também demonstra resultados superiores à quimioterapia convencional. Os linfomas da zona do manto e os de baixo grau constituem situações especiais. Os primeiros apresentam sobrevida curta após o diagnóstico e o transplante pouco altera os resultados nos estádios refratários e na segunda remissão. Nos linfomas de baixo grau, principalmente os com reação em cadeia da polimerase (PCR) negativa para o bcl2, apresentam sobrevida livre de doença de 50 a $60 \%$ em ensaios clínicos iniciais ${ }^{(25)}$.

6) Leucemia mielóide crônica: pacientes jovens sem doadores na família e sem doador não aparentado podem beneficiar-se de transplante autólogo com stem cells periféricas, principalmente se o enxerto tiver grande quantidade de células $\mathrm{Ph} 1$ negativas.

\section{IMUNOTERAPIA PÓS-TMO}

\subsection{Evidências do efeito enxerto-contra-tumor em TMO alogênico}

As primeiras evidências do efeito antitumoral no TMO foram descritas por Weiden et al. ${ }^{(26)}$, do grupo de Seattle, quando os autores perceberam uma menor incidência de recidiva naqueles pacientes que desenvolviam doença do enxerto-contra-hospedeiro (GVHD).

Foram descritos dois pacientes cuja leucemia (LLA) recidivara precocemente, após o TMO alogênico, e que desaperecera durante a agudização da GVHD, e, após algum tempo, recidivara novamente. Um terceiro paciente, cujo linfoma de Burkitt recidivara um mês após o TMO, tivera a ciclosporina inter- 
rompida, desenvolvera GVHD e apresentara remissão do linfoma; ao receber ciclosporina e prednisona pela piora da GVHD, apresentou recidiva do linfoma e veio a óbito ${ }^{(27,28)}$.

Ao se comparar a incidência de recidiva em receptores de medula óssea, que não têm risco para desenvolver GVHD e medula alogênica, ver-se-á que o retorno da leucemia é maior no grupo singênico do que no alogênico. Os dois grupos foram comparáveis quanto ao diagnóstico, idade e intervalo do diagnóstico até o TMO e regimes de condicionamento recebidos. Em trabalhos com análise multivariada, demonstrouse que a GVHD foi o fator independente mais significante, associado com a diminuição da recidiva.

Em recente análise de 1.198 pacientes de Seattle, com alta probabilidade de recidiva, verificouse que a GVHD foi o principal fator associado com a sobrevida. Na análise estatística de regressão, utilizando-se a GVHD aguda e a crônica como variáveis independentes, os mesmos autores demonstraram que a GVHD esteve associada com a menor recidiva ${ }^{(29)}$.

Outro dado impressionante foi um estudo comparativo entre duas populações, que revelou taxa de recidiva, entre 79 pacientes receptores de TMO alogênico e depletado de células $\mathrm{T}$, semelhante à de um grupo de 46 pacientes receptores de TMO singênico. Os resultados, nas duas populações diferentes quanto ao diagnóstico e fase da doença, sugerem que a GVHD clínica foi um pré-requisito para o efeito enxerto-contra-leucemia (ECL ou GVL) ${ }^{(26)}$. O efeito ECL está associado à presença de células T. Verificou-se que pacientes que receberam medula óssea depletada de células T tiveram mais recidiva. Assim, um estudo com 405 pacientes transplantados, provenientes de 82 centros, em 27 países, a incidência de recidiva em pacientes com LMC em fase crônica foi de $10 \%$ com medula óssea não-depletada e GVHD moderado a severo, e de $50 \%$ com medula depletada de células T com GVHD leve ou ausente ${ }^{(30)}$.

\subsection{Abordagens imunoterapêuticas pós-TMO}

O emprego da imunoterapia antitumoral está baseado na lenta recuperação da imunidade após o transplante. Vários agentes têm sido empregados com tal finalidade, assim como a infusão de buffy coat ou donor lymphocyte infusion para os transplantes alogênicos, cuja finalidade é a de induzir um efeito enxerto-contra-leucemia. O uso de drogas imunomoduladoras também é atraente, pois elas atuam sobre as células tumorais, mas não sobre as células normais. Destacamos, neste capítulo, o emprego clíni- co da interleucina-2 (IL-2), com a qual temos experiência pessoal.

A interleucina-2, conhecida anteriormente como fator de crescimento das células T, é capaz de ativar também as células NK (natural killer), gerando uma atividade citotóxica, denominada de lymphokineactivated killer cell (LAK acitivity). Em ensaios biológicos, as células LAK foram capazes de induzir a lise de linhagens tumorais não restritas ao HLA. Além disso, Higuchi et al. descreveram que as células LAK apareciam até seis meses após o transplante autólogo de medula óssea ${ }^{(31)}$.

Com o auxílio de técnicas de biologia molecular, altamente sensíveis, está se tornando claro que a doença residual mínima pode persistir após o TMO e não necessariamente levar a uma recidiva citogenética ou clínica, especialmente na leucemia mielóide crônica (LMC). Neoplasias secundárias, tais como doenças linfoproliferativas de células B, podem se desenvolver como uma complicação do regime de condicionamento, reativação viral ou imunossupressão e devem ser distinguidas de uma recidiva da doença primária ${ }^{(32)}$.

A profilaxia com outras citocinas, como os interferons, pode ser efetiva na prevenção da recidiva em pacientes de alto risco, que foram submetidos ao transplante de medula óssea. A leucemia que recidiva após o regime de condicionamento para transplante de medula é geralmente considerada incurável. As opções para uma terapia pós-transplante de medula óssea incluem quimioterapia adicional, agentes indutores de diferenciação, imunoterapia com várias citocinas para induzir os efeitos enxerto-contra-leucemia (GVL) e, finalmente, um segundo transplante de medula óssea para determinados pacientes. Os índices de sucesso de um segundo transplante são baixos, enquanto que os índices de complicação fatal, incluindo toxicidades relacionadas ao regime de condicionamento, como a doença venoclusiva (VOD) e a pneumonite intersticial, são altos.

Existe uma considerável evidência de que, dentre os mecanismos imunológicos, particularmente, o efeito GVL seja um dos benefícios terapêuticos no transplante de medula óssea. Vários grupos têm estudado a viabilidade do uso de citocinas na manipulação da resposta imune do doador ou do receptor contra células leucêmicas residuais, para aumentar ou criar o efeito GVL, após o transplante autólogo ou alogênico de medula óssea ${ }^{(32,33)}$. Um desses estudos buscou identificar pacientes com alto risco de recidiva após transplante, com base em fatores de risco já estabelecidos 
e tratá-los com interleucina-2 (IL-2) ou interferon- $\alpha$, logo após o transplante de medula óssea, para aumentar as células natural killer (NK) e/ou a atividade de outras células killer para diminuir o risco da recidiva.

O grupo do hospital Dana-Farber, em Boston, além de outros investigadores, estudaram o impacto da infusão prolongada de baixas doses de IL-2 após o transplante autólogo e alogênico com depleção de células T. Treze pacientes receberam IL-2 em doses de $2 \times 10^{5} \mathrm{U} / \mathrm{m}^{2} /$ dia sob infusão intravenosa contínua, por 90 dias, iniciada a uma mediana de 85 dias após o transplante. A toxicidade foi mínima. Todos os pacientes demonstraram um aumento relevante no número e na atividade das células NK.

A decisão de se tratar um paciente agressivamente, quando da recidiva da leucemia após o transplante de medula óssea, é difícil. Questões de qualidade de vida devem ser pesadas cuidadosamente, e é preciso contrabalançar os riscos e benefícios em se tratar com um segundo transplante contra a escolha de uma terapia alternativa ou somente uma terapia de suporte $^{(33)}$.

\subsection{Imunoterapia pós-TMO autólogo com in- terleucina-2}

O sucesso do autotransplante de medula óssea para pacientes com leucemia aguda ou linfoma está limitado, em parte, pela alta incidência de recidivas após o TMO, atribuível às células malignas residuais que sobreviveram ao regime de condicionamento e/ou que foram infundidas com a medula óssea. A imunoterapia pós-TMO com IL-2, possuindo atividade antitumoral especifica, representa um meio de erradicar essas células residuais ${ }^{(34)}$.

A IL-2 é produzida pelos linfócitos T, estimula a proliferação de células $\mathrm{T}$ e induz a secreção de outras citocinas, tais como interferon-gama e o fator de necrose tumoral (TNF), além de aumentar a função citolítica dos linfócitos $\mathrm{T}$ e das células natural killers (NK).

O tratamento com IL-2 associada a células LAK tem induzido remissões em pacientes com neoplasia hematológica avançada. Em seis estudos Fase I/II com IL-2 e LAK, administrados a um total de 56 pacientes com Doença de Hodgkin e linfomas não-Hodgkin resistentes à quimioterapia convencional, uma variedade de respostas foram observadas ${ }^{(35)}$. Foa et al. ${ }^{(36)}$ relataram o uso de IL-2 em 12 pacientes com LMA, que recidivaram ou eram resistentes à quimioterapia. Embora nenhuma resposta tenha sido observada em sete pacientes, quatro remissões completas foram ob- tidas em cinco pacientes com $<15 \%$ de blastos na medula óssea. Um paciente, que foi tratado para LMA em terceira recidiva, permanece em remissão completa por aproximadamente 30 meses após o tratamento com IL-2. Em outro estudo de fase II, administrando IL-2 em pacientes refratários à quimioterapia, dois entre 16 pacientes com LMA em recidiva tiveram remissão completa e dois tiveram remissão parcial $^{(37)}$. Lim et al. relataram três pacientes com LMA em recidiva tratados com IL-2, sendo que um paciente entrou em terceira remissão completa que durou mais do que seis meses ${ }^{(37 a)}$.

O tratamento com IL-2, em pacientes com leucemia e linfoma, tem induzido remissões prolongadas após transplante autólogo (Figura 1). Nessa situação, as células LAK estão aumentadas (Figura 2). Assim, Massumoto et al. ${ }^{(38)}$ demonstraram que o uso de IL2 em altas doses induziu alterações cutâneas pós-transplante, que se assemelhavam muito à doença enxertocontra-hospedeiro cutânea, vista no transplante alogênico. Todos os pacientes haviam se submetido a um transplante autólogo e, em 70\% deles, observaram-se tais alterações cutâneas. Um conceito especulativo desses resultados seria o da resposta imunológica contra o tumor, induzida pela IL-2.

Resultados preliminares de A. Mazumder da Universidade de Georgetown, EUA (comunicação pessoal) indicam que, todas as 15 pacientes portadores de câncer de mama, que tiveram stem cells ativadas com IL-2, conseguiram a reconstituição hematopoética. A mediana de recuperação de granulócitos foi de 11 dias (variação de 09-15 dias). Em termos de toxicidade, nenhum paciente desenvolveu grau IV nas primeiras 24 horas após a infusão de stem cells ativadas pela IL-2. Uma paciente, dentre 15, desenvolveu hematúria, entretanto, ela havia recebido ciclofosfamida e carboplatina, que são drogas que provocam cistite hemorrágica. Nenhum óbito ocorreu em tal série.

Klingemann et al. relataram resultados preliminares em pacientes que receberam IL-2 imediatamente após a medula óssea ativada com IL-2. Após um regime de condicionamento com bussulfan e ciclofosfamida, pacientes com Leucemia Mielóide Aguda de alto risco receberam medula óssea ativada com IL-2, seguida de sete dias de doses escalonadas de IL-2. As principais toxicidades observadas foram febre e mal-estar. A IL-2 foi interrrompida em um paciente devido à piora da função renal, hipotensão e fibrilação atrial. A recuperação mielóide ocorreu no dia +49 pós-TMO (variação de 20-71 dias) e a de plaquetas em 98 dias $^{(39)}$. 


\section{IL-2/LAK Therapy after ABMT for Lymphoma}

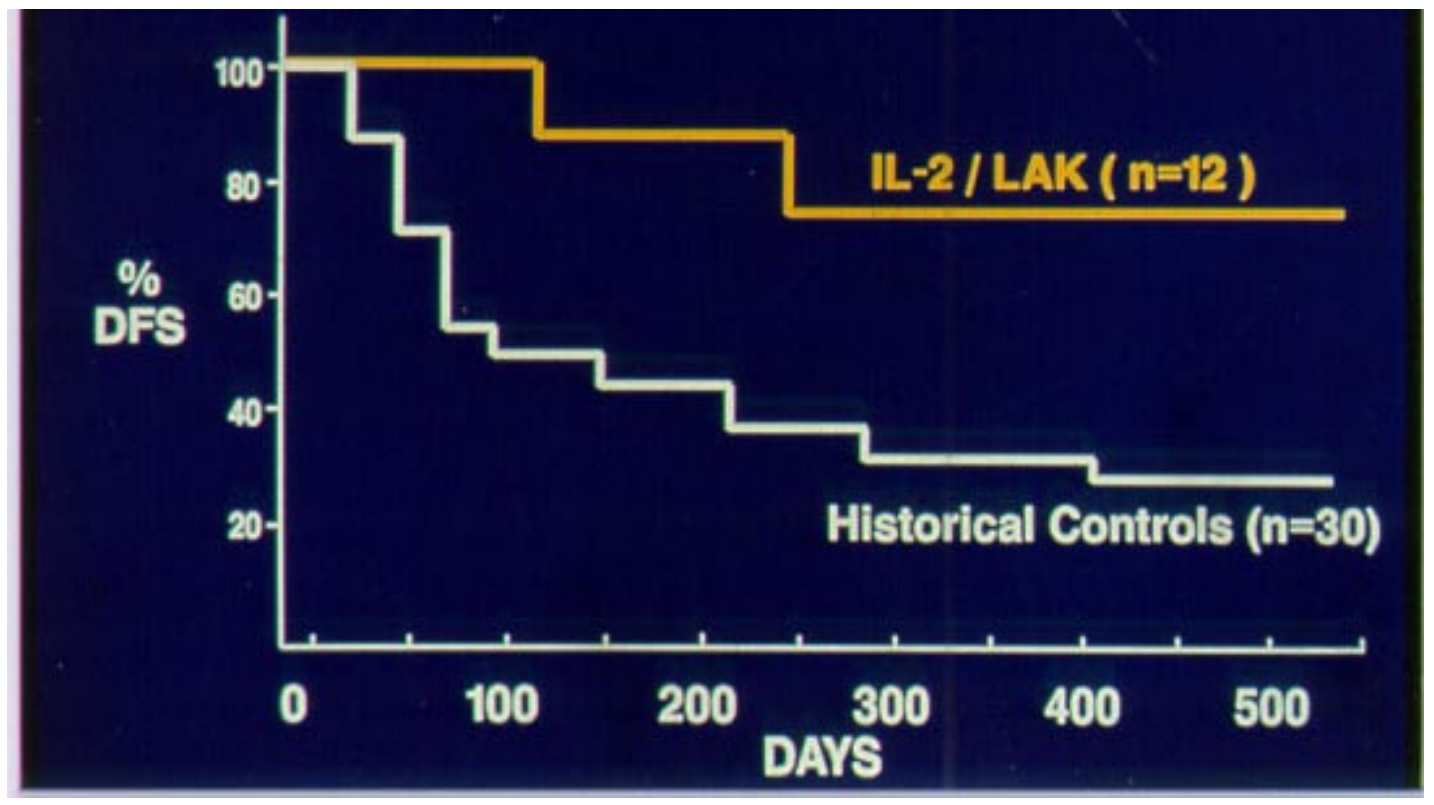

Figura 1: Prolongamento da sobrevida de pacientes portadores de linfomas tratados com IL-2 e células LAK após o transplante autólogo de CTH. DFS: Disease-free survival. ABMT: Autologous Bone Marrow Transplantation.

\section{IL-2 After Autologous BMT Circulating LAK Activity}

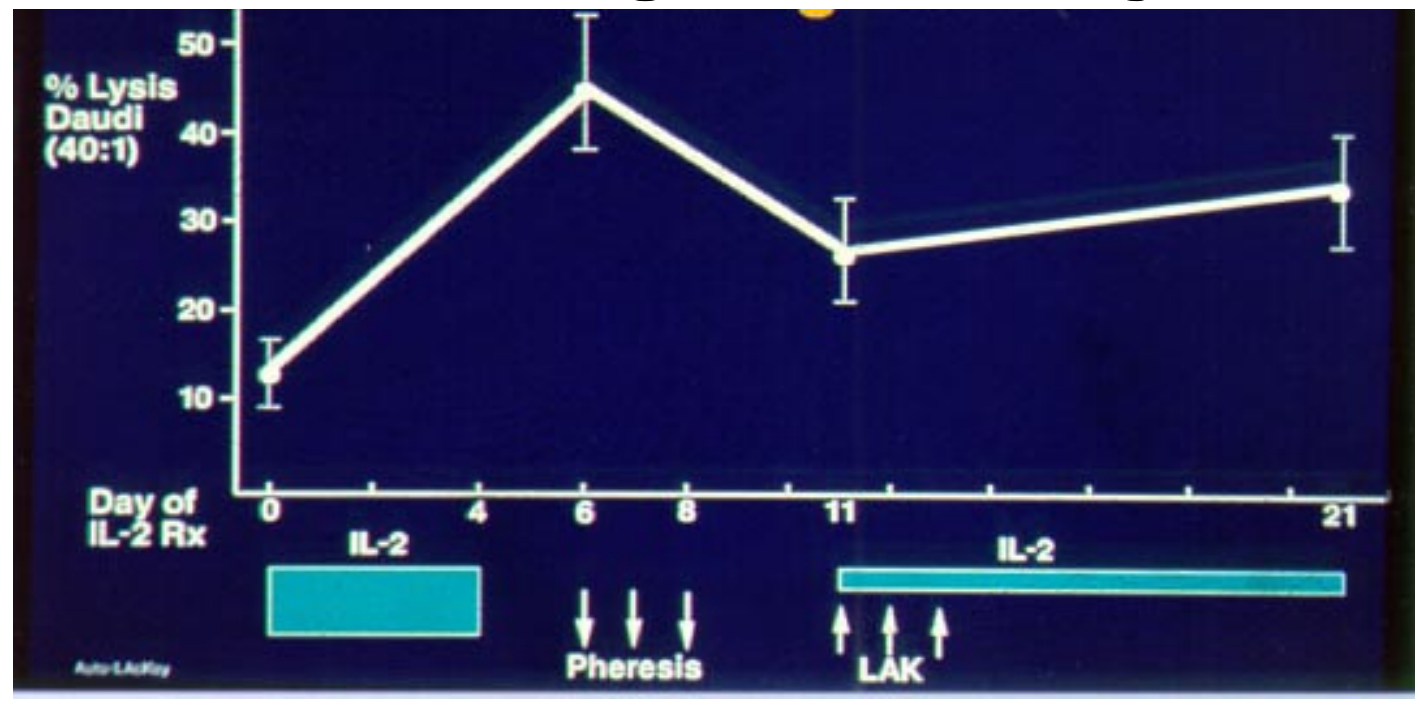

Figura 2: Aumento da atividade citotóxica de células LAK em pacientes tratados com IL-2 e células LAK após transplante autólogo de CTH. 
MASSUMOTO C \& MIZUKAMI S. Autologus bone marrow transplantation and posttransplantat immunotherapy.

Medicina, Ribeirão Preto, 33: 405-414, oct./dec. 2000.

RESUMO: High dose chemotherapy followed by stem cell rescue is the treatment of choice for a variety of solid tumors and hematologic malignancies. The autologous bone marrow transplantation is associated with low mortality rate in comparison to allogeneic transplantation. However, the relapse rate is higher than allogeneic and similar to singeneic transplantation and clinical results depend on the nature and stage of primary disease. Disease free survival is higher when autologous patients are transplantated in remission or with minimal residual disease and it is reduced when transplantation is performed in advanced stages. Cellular adoptive immunotherapy refers to the use of allogeneic lymphocytes as antitumor agents. On the other hand, the rationale for using Interleukin-2 in autologous bone marrow transplantation setting is the absence of immunological barrier between donor and recipient and the possible elimination of residual cells that were infused with marrow cells. As relapse occurs in the first months posttransplant, immunotherapy must be used early in the context of minimal residual disease.

UNITERMS: Bone Marrow Transplantation. Transplantation, Autologous. Interleukin-2. Immunotherapy.

\section{REFERÊNCIAS BIBLIOGRÁFICAS}

1 - GULATI SC; YAHALOM J \& PORTLOCK C. Autologous bone marrow transplantation. Curr Probl Cancer 15:1-57, 1991.

2 - ROCHA V; CHASTANG CL; SOUILLET G; PASQUINI R; PLOUVIER E; NAGLER A; LOCATELLI F; SAARINEN U; CORNU G; BERNAUDIN F \& GLUCKMAN E. Related cord blood transplant: the Eurocord experience from 78 transplants. Bone Marrow Transplant 21:59-62, 1998.

3 - GORIN NC; LOPEZ M; LAPORTE JP; QUITTET P; LESAGE S; LEMOINE F; BERENSON RJ; ISNARD F; GRANDE M \& STACHOWIAK J. Preparation and sucessful engraftment of purified CD34+ bone marrow progenitor cells in patients with non-Hodgkin's lymphoma. Blood 85:1647-1654, 1995.

4 - JUTTNER CA; TO LB; HAYLOCK DN; BRANFORD A \& KIMBER RJ. Circulating autologous stem cells collected in very early remission from acute non-lyphoblastic leukaemia produce prompt but incomplete haemopoietic reconstitution after high dose melphalan or supralethal chemoradiotherapy. Brit $\mathbf{J}$ Haematol 61:739:745, 1985.

5 - STORB R; THOMAS ED; BUCKNER CD; CLIFT RA; JOHNSON FL; FEFER A; GLUCKSBERG H; GILBLETT ER;LEMER KG \& NEIMAN P. Allogeneic marrow grafting for treatment of aplastic anemia. Blood 43: 157-180, 1974.

6 - ELLIOTT C; SAMSON SM; ARMITAGE S; LYTTELTON MP; MCGUIGON D; HARGREAVES R; GILEES C; ABRAHAMSON G; ABBOUDI Z; BRENNAN M \& KANFER EJ. When to harvest peripheral-blood stem cells after mobilization therapy. Prediction of CD34-positive cell yield by preceding day CD34-positive concentration in peripheral blood. J Clin Oncol 14:970973, 1996.

7 - PASSOS COELHO JL; BRAINE HG; DAVIS JM; HUELSKAMP AU; SCHEPERS KG; OHLY K; CLARKE B; WRIGHT SK; NOGA SJ \& DAVIDSON NE. Predicitive factors for peripheral blood progenitor cell collections using a single large volume leukapheresis after cyclophosphamide and granulocyte-macrophage colony-stimulating factor mobilization. J Clin Oncol 13:705-714, 1995.
8 - ROWLEY DS. Hematopoietic stem cell cryopreservation: a review of current techniques. J Hematother 1: 233-250, 1992.

9 - MASSUMOTO CM; MIZUKAMI S; CAMPOS MF; SILVA LAG ; MENDRONE JUNIOR A; SAKASHITA A; ZAMBON E; OSTRONOFF M; MACEDO MC; MEDEIROS RC; DORLHIAC P; CHAMONE D \& DULLEY F. Criopreservação de medula óssea utilizando um congelador programável: experiência em 86 congelamentos. Rev Assoc Med Bras 43:93-98, 1997.

10 - MASSUMOTO CM; MENDRONI A; CARBONELL AL; MOTA MA \& MIZUKAMi S. Mobilização e coleta de células-tronco hematopoéticas de sangue periférico. Rev Hem Hemot 2: 224-27, 1996.

11 - KRAUSE DS; JO FLACKLER M; CIVIN CI \& STRATFORD MW. CD34: structure, biology and clinical utility. Blood 87:1-13, 1996.

12 - MASSUMOTO CM; MIZUKAMI S; CAMPOS MF; SILVA LAG; TUTIYA I; BEITLER B \& MELO N. Determinação de células CD34 postivas no sangue periférico: otimização de método utilizando-se associadamente anticorpo monoclonal anti CD14. Rev Bras Anal Clin 29:89-92, 1997.

13 - PAPAYANNOPOULOU T; PRIESTLEY GV \& NAKAMOTO B. Anti-VLA4/VACM-1 induced mobilization requires cooperative signaling through the kit/kit ligant pathway. Blood 91:2231-2239, 1998.

14 - TO LB; SHEPPARD KM; HAYLOCK DN; DYSON PG; CHARLES P; THORPE DL; DALE BM; DART GW; ROBERTS MM \& SAGE $\mathrm{RE}$. Single high doses of cyclophosphamide enable the collection of high numbers of hematopoietic stem cells from the peripheral blood. Exp Hematol18:442-447, 1989.

15 - SHUMART MC \& MCDONALD GB. Gastrointestinal and hepatic complications. In: FORMAN SJ; BLUME KG \& THOMAS ED. Bone marrow transplation. Blackwell Scientific Publications, Boston, p. 457, 1994.

16 - LONG GD \& BLUME KG. Allogeneic and autologous marrow transplantation. In: BEUTLER E; LICHTMAN MA; COLLER BS \& KIPPS JJK. Willians Hematology. 5th. ed.MacGraw-Hill, New York, p. 172-194, 1995. 
17 - PICO JL, OSTRONOFF M \& DROZ JPI. High dose chemotherapy with cisplatin, etoposide and cyclophosphamide (PEC protocol) followed by autologous bone marrow support in non-seminomatous germ cell tumors. Proc Am Soc Clin Oncol 8: 12, 1989.

18 - STADTMAUER EA; O'NEILLA, GOLDSTEIN LJ \& CRILLEY P Phase III randomized trial of ;igh-dose chemoterapy (HDC) and stem cell support (SCT) shows no difference in overall survival or severe toxicity compared to maintance chemotherapy with cyclophosphamide, methotrexate and 5-fluoracil (CMF) for women with metastatic breast cancer who are responding to conventional induction chemotherapy: The Philadelphia Intergroup Study (PBT-1). Proc Am Soc Clin Oncol 18:1a.,1999.

19 - SHINOZUKA T; MURAKAMI M \& MIYAMOTO T . Hogh dose chemotherapy (HDC) with autologous bone marrow transplantation (ABMT) in ovarian cancer. Proc Am Soc Clin Oncol 10:193, 1991.

20 - STIFF PJ; BAYER R; KERGER C; POTKUL RK; MALHOTRA D; PEACE DJ; SMITH D \& FISHER SG. High-dose chemotherapy with autologous transplantation for persistent relapsed ovarian cancer: a multivariate analysis of survival for 100 consecutively treated patients. J Clin Oncol 15:1309-1317, 1997.

21 - SCHMITZ N; DREGER P; ZANDER A;EHNINGER G; WANDT H; FAUSER AA; KOLB HJ; ZUMSPREKELA; MARTINA \& HECHT T. Results of a randomized controlled, multicentre study of recombinant human granulocyte colony-stimulating factor (filgrastim) in patients with Hodgkin's disease and nonHodgkin's lymphoma undergoing autologous bone marrow transplantation. Bone Marrow Transpl 15:261-266, 1995.

22 - GORIN NC; LABOPIN M; LAPORTE JP; DOUAY L; LOPEZ M; LESAGE S; FOUILLARD L; ISNARD F; JOUET JP; BELLAL N; PEROT C; VAN DEN AKKER J; BAUTERS F \& NAJMAN A. Importance of marrow dose on posttransplant outcome in acute leukemia: models derived from patients autografted with mafosfamide-purged marrow at a single institution. Exp Hematol 27: 1822-1830, 1999.

23 - LAPORTE GF \& LARSON RA. Treatment of acute lymphoblastic leukemia. Semin Oncol 24:70-78, 1997.

24 - ATTAL M; HAROUSSEAU JL; STOPPA AM; SOTTO JJ; FUZIBET JG; ROSSI JF; CASASSUS P; MAISONNEUVE H; FACON T; IFRAH N; PAJEN C \& BATAILLE R. A prospective randomized trial of autologous bone marrow transplantation and chemotherapy in multiple myeloma. N Engl $\mathbf{J}$ Med 335:91-97, 1996.

25 - GIANNI AM; BREGNI M, SIENA S; BRAMBILLA C; DI NICOLA M; LOMBARDI F; GANDOLA L; TARELLA C; PILERI A; RAVAGNANI F; VALAGUSSA P \& BONADONNA G. Highdose chemotherapy and autologous bone marrow transplantation compared with MACOP-B in aggressive B-cell lymphoma. N Engl J Med 336:1290-1297, 1997.

26 - WEIDEN PL; SULLIVAN KM; FLOURNOY N; STORB R \& THOMAS ED. Antileukemic effect of chronic graft-versus-host disease. N Engl J Med 304:1529-1533,1981.

27 - ODOM L; AUGUST C; GITHENS J \& HUMBERT J. Graft-versus leukemia reaction following bone marrow transplantation for acute lymphoblastic leukemia. O'KUNEWICK \& MEREDITH, ed. Graft-versus-leukemia in man and animal models. Boca Raton, CRC Press, p.25-43, 1981.
28 - ODOM L; AUGUST C \& GITHENS J. Remission of relapsed leukaemia during graft-versus-host reaction: A "graft-versus-leukaemia" in man? Lancet 2:537-540, 1978.

29 - SULLIVAN K; WEIDEN P \& SOTRB R. Influence of acute and chronic graft-vs-host disease on relapse and survival after bone marrow transplantation from HLA-identical siblings as treatment of acute and chronic leukemia. Blood 73:17201728, 1989.

30 - GOLDMAN JM; GALE RP \& HOROWITZ MM. Bone marrow transplantation for chronic myelogenous leukemia in chronic phase. Increased risk for relapse with T-cell depletion. Ann Intern Med 108: 806-814, 1988.

31 - HIGUCHI CM; THOMPSON JA; COX T \& FEFER A. Lymphokine-activated killer function following autologous bone marrow transplantation for refractory hematological maligancies. Cancer Res 49:5509-5513, 1989.

32 - SNYDER DS. Management of relapse after bone marrow transplantation. In: FORMAN SJ; BLUME KG \& THOMAS ED, eds. Bone marrow transplantation. Blackwell Scientific, Boston, p. 545-553, 1994

33 - KLINGEMANN HG \& PHILIPS GL. Immunotherapy after bone marrow transplantation. Bone Marrow Transpl 8:73-81, 1991.

34 - HESLOP HE; GOTTLIEB DJ \& BIANCHI ACM. In vivo induction od gamma interferon and tumor necrosis factor by Interleukin2 infusion following intensive chemotherapy or autologous marrow transplantation. Blood 74:1374-1380, 1989.

35 - URBA W \& SZNOL M. IL-2 in patients with malignant lymphoma. The US experience. Proceedings. NCI-INSERM Workshop on the use of IL-2 in hematologic malignancies. 1991.

36 - FOA R; MELONI G \& TOSTI S. Treatment of residual disease in acute leukemia patients with recombinant Interleukin-2 (IL2): Clinical and biological findings. Bone Marrow Transpl 6:98-102, 1990

37 - MARANINCHI D; BLAISE D \&VIENS P. High dose recombinant Interleukin-2 and acute myeloid leukemias in relapse. Blood 78:2182-2187, 1991.

37a- LIM SH; NEWLAND AC; KELSEY S; BELL A; OFFERMAN E; RIST C; GOZZARD D; BAREFORD D; SMITH MP \& GOLDSTONE AH. Continuous intravenous infusion of high dose recombinant interleukin-2 for acute myeloid leukemia - a phase II study. Cancer Immunol Imunother 34: 337-342, 1992.

38 - MASSUMOTO CM; BENYUNES MC; SALE G; BEAUCHAMP M; YORK A; THOMPSON JA; BUCKNER CD \& FEFER A . Close simulation of acute graft-versus-host disease by interleukin-2 administered after autologous bone marrow transplantation for hematologic maligancies. Bone Marrow Transplant 17:351-356, 1996.

39 - KLINGEMAN H; EAVES CJ; BARNETT MJ; EAVESAC; HOGGE DE; MANTEL SH; REECE E; SHEPHERD JD; SUTERLAND HJ \& PHILIPS GL. Transplantation of patients with high risk acute myeloid leukemia in first remission with autologous marrow cultured in Interleukin-2 followed by Interleukin-2 administration. Bone Marrow Transpl 14: 389-396, 1994.

Recebido para publicação em 25/10/2000

Aprovado para publicação em 20/12/2000 